\title{
HISTORICIDADE E CONTEMPORANEIDADE DO CONCEITO DE PAISAGEM
}

\section{Historicity and Contemporary Concept of Landscape}

\author{
Marcelo Martins de Moura-Fé \\ Geógrafo. Doutorando em Geografia \\ Programa de Pós-Graduação em Geografia - Universidade Federal do Ceará - UFC \\ mourafe.marcelo@yahoo.com.br
}

Artigo recebido em 21/03/2014 e aceito para publicação em 24/11/2014

http://dx.doi.org/10.12957/tamoios.2014.9975

\begin{abstract}
Resumo
O conceito de Paisagem, desde sua gênese, apresenta perspectivas básicas de análise, compartimentadas nos aspectos morfológicos e fisiológicos. Na sua retomada, nos anos 1970, o âmbito analítico desse conceito-chave do conhecimento geográfico foi ampliado, ao agregar às suas perspectivas básicas, as abordagens culturais e simbólicas, fundamentais para a inserção da sociedade no centro das discussões. Seguindo essa linha imbricada de sucessão, atualmente tem-se abordagens que constituem exercícios de síntese, as Unidades de Paisagem, e ainda mais ampla, a Ecologia da Paisagem. Essas diversas abordagens tem aspectos comuns, os quais garantem unidade e diversidade de aplicações do conceito de Paisagem na Geografia.

Ambiental.

Palavras-chave:Paisagem,Conceito-Chave,Geografia,GeografiaFísica,Análise

Abstract

The concept of landscape, from its genesis, presents basic perspectives of analysis, compartmentalized in morphological and physiological aspects. At its resumed in the 1970s, the analytical framework of this key concept of geographical knowledge was expanded to add to their basic perspectives, the cultural and symbolic approaches, fundamental for the integration of the society at the center of discussions. Following this line imbricated succession, it has currently approaches that constitute exercises synthesis, the Landscape Units, and even more broadly, the Landscape Ecology. These approaches have several common features, which guarantee unity and diversity of applications of the concept of landscape in geography.
\end{abstract}

Keywords: Landscape, Key Concept, Geography, Physical Geography, Environmental

Analysis. 


\section{INTRODUÇÃO}

Há uma controvérsia sobre a matéria tratada pela Geografia, que se manifesta na indefinição do objeto desta ciência, a qual apoia-se no próprio significado etimológico do termo Geografia descrição da Terra, onde caberia ao geógrafo descrever todos os fenômenos manifestados na superfície da Terra, em uma espécie de síntese de todas as ciências (MORAES, 1998).

De acordo com Moraes (1998), esta concepção originou-se a partir das formulações de Imanuel Kant, que postulou a existência de duas classes de ciências, as especulativas, apoiadas na razão, e as empíricas, apoiadas na observação e nas sensações. Ao nível do segundo grupo, haveria duas disciplinas de síntese, a Antropologia, síntese dos conhecimentos relativos ao homem, e a Geografia, síntese dos conhecimentos sobre a natureza.

Desta forma, a tradição kantiana coloca a Geografia como uma ciência sintética (que trabalha com dados de todas as demais ciências), descritiva (que enumera os fenômenos abarcados) e que visa abranger uma visão de conjunto do planeta. Esta perspectiva é denominada de corológica (visão espacial, em oposição à cronológica ou enfoque temporal) (MORAES, 1998).

A ideia de descrição da superfície terrestre alimentou a corrente majoritária do pensamento geográfico, porém, outros autores vão definir a Geografia como o estudo da Paisagem, ao passo que a análise geográfica estaria nos aspectos visíveis do real (MORAES, 1998). Todavia, a Paisagem posta como objeto específico da Geografia, é vista como uma associação de múltiplos fenômenos, o que contribui para a manutenção da concepção de ciência de síntese.

Esta perspectiva apresenta duas variantes básicas e essenciais para a apreensão da Paisagem: uma, mantendo a tônica descritiva, que se deteria na enumeração dos elementos presentes e na discussão das formas, denominada de morfológica. A outra se preocuparia mais com a relação entre os elementos e com a dinâmica destes, apontando para um estudo de fisiologia, isto é, do funcionamento da Paisagem.

A partir dessas duas linhas conceptivas básicas derivaram outras, vinculadas estreitamente aos seus contextos espaço-temporais. Este trabalho apresentará um quadro evolutivo do conceito, passando pela sua origem até chegar nas concepções contemporâneas de paisagem, traçando paralelos entre elas e apontando elementos comuns, os quais podem ser utilizados, notadamente, no âmbito da Geografia.

\section{MATERIAIS E MÉTODOS}

A natureza da pesquisa fundamentou-se em uma abordagem de cunho qualitativo, que de acordo com Gil (1996) visa a compreensão ou interpretação de processos de forma complexa e contextualizada e se caracteriza como um plano aberto e flexível. 
No tocante às técnicas de pesquisa, os procedimentos desenvolvidos foram baseados em um criterioso levantamento bibliográfico, realizando um estudo sistematizado e investigando materiais publicados, sobretudo, em periódicos de revistas científicas estrangeiras e nacionais, com levantamento dos principais referenciais teóricos sobre o conceito de paisagem.

Para a elaboração desse trabalho foram realizadas revisões e análises detalhadas no campo da literatura científica clássica e atual versada sobre o conceito de Paisagem e em temas correlatos, cujos materiais, previamente triados no tocante à sua relevância e pertinência, embasaram a discussão apresentada, centrada na historicidade do conceito e seus aspectos contemporâneos no âmbito da Ciência Geográfica.

\section{RESULTADOS E DISCUSSÃO}

\section{Perspectivas Básicas da Análise da Paisagem}

O conceito de paisagem foi originalmente ligado ao positivismo, na escola alemã, numa forma mais estática, onde se focalizam os fatores geográficos agrupados em unidades espaciais, com ênfase para seus aspectos superficiais e, numa forma mais dinâmica, na geografia francesa, onde o caráter processual é mais importante, com destaque para o funcionamento da paisagem. Ambas tratam a paisagem como uma face material do mundo, onde se imprimam as atividades humanas (SCHIER, 2003).

\section{A Perspectiva Morfológica}

Humboldt (que tinha como formação básica a de naturalista) e Ritter (historiador e filósofo), juntando seus conhecimentos, lançaram as bases para a sistematização da Ciência Geográfica, tendo como objetivo primordial a compreensão dos diferentes lugares através da relação dos homens com a natureza, sendo que para isso, era necessário o conhecimento dos aspectos físico-naturais das paisagens, assim como dos aspectos humanos e sociais (MENDONÇA, 1997).

A perspectiva da morfologia apresenta em sua gênese, fundamentos oriundos da Estética. Em termos de método, Humboldt propõe o "empirismo raciocinado", isto é, a intuição a partir da observação, ou seja, o geógrafo deveria contemplar a Paisagem de uma forma quase estética. A Paisagem causaria no observador uma "impressão", que combinada com a observação sistemática dos seus elementos componentes e filtrada pelo raciocínio lógico, levaria à explicação da causalidade das conexões contidas na Paisagem observada, desta contemplação adviria a explicação (MORAES, 1998). Daí a grande valorização da intuição nos procedimentos de análise propostos por esta perspectiva, dela decorrendo uma considerável carga subjetiva no pensamento geográfico.

Vale ressaltar que essa perspectiva descritiva da Paisagem não deve ser interpretada como algo superado, tendo em vista que tal perspectiva permeia nosso cotidiano. Como exemplo prático nos 
basta uma consulta a qualquer pequeno dicionário da língua portuguesa e verificar a definição desse conceito: "Paisagem: espaço de terreno que se abrange numa visão de conjunto; vista, panorama; pintura, gravura ou desenho que representa uma vista panorâmica" (XIMENES, 2003, p. 690).

\section{Perspectiva Fisiológica}

A perspectiva da fisiologia da Paisagem vai se fundamentar na Biologia, em particular na ideia de organismo, onde a Paisagem seria um organismo com funções vitais e com elementos que interagem. À Geografia caberia perceber e entender estas inter-relações entre fenômenos de qualidades distintas, coabitantes de uma determinada porção do espaço terrestre. Esta perspectiva introduz a Ecologia no domínio geográfico (MORAES, 1998; MENDONÇA, 1997).

Desta forma, a Geografia seria uma disciplina eminentemente sintética, preocupada com a conexão entre os elementos, e buscando através dessas conexões, a causalidade existente na natureza (MORAES, 1998), além de manter uma considerável distância da atuação humana nas configurações e nos delineamentos evolutivos da Paisagem.

\section{Evolução e Contemporaneidade do Conceito}

A importância da Paisagem na história do pensamento geográfico tem variado ao longo do tempo, tendo sido relegado a uma posição secundária durante os predomínios dos discursos vinculados às escolas da Geografia Clássica, da Nova Geografia e da Geografia Crítica, suplantado pela ênfase nos conceitos de Região, Espaço, Território e Lugar (CORRÊA e ROSENDAHL, 1998).

A retomada do conceito de Paisagem se verificou após 1970 e trouxe novas acepções fundadas em outras matrizes epistemológicas. Esse período viu também o surgimento da Geografia Humanista que foi, na década seguinte, acompanhado da retomada da Geografia Cultural. Assentada na subjetividade, na experiência e no simbolismo, a Geografia Humanista permite que a Paisagem tornase um conceito revalorizado, assim como a Região, enquanto o conceito de Território tem na Geografia humanista uma das suas matrizes. O Lugar passa a ser o conceito-chave mais relevante, enquanto o Espaço adquire, para muitos autores, o significado de espaço vivido (CORRÊA e ROSENDAHL, 1998; CORRÊA, 1995).

Essencialmente, o conceito de Paisagem permanece com suas dimensões morfológica e funcional. Todavia, o conceito apresenta variações, ao abranger a ação humana e a dimensão histórica em diálogo com a dimensão espacial, esta já tão peculiar ao conceito, o que derivou na apreensão de significados, expressando valores, crenças, mitos e utopias, ou seja, na obtenção de uma dimensão simbólica (CORRÊA e ROSENDAHL, 1998) e conciliando ainda interesses sociais e ecológicos numa visão do desenvolvimento sustentável (SCHIER, 2003).

Sendo assim, a Paisagem passa a ser algo maior do que uma imagem observada num lugar a partir de um determinado ponto de vista, ao se constituir numa forma de integração, que ainda se faz 
necessária definir com precisão (MONTSERRAT, 1990).

Esta multiplicidade de dimensões será apresentada nos tópicos que se seguem, baseados em estudos que datam de momentos distintos da história do pensamento geográfico, representando posições distintas e complementares do mesmo objeto, o conceito de Paisagem, a Paisagem Geográfica.

\section{A Morfologia da Paisagem}

A Paisagem geográfica, apresentada como um conceito de unidade da Geografia, elaborado para caracterizar a associação peculiarmente geográfica dos fatos, vista como um conjunto de formas naturais e culturais associadas em uma dada área é analisada morfologicamente através da integração das formas entre si e o caráter orgânico, ou quase orgânico, delas. Porém, os fenômenos que compõem uma área não estão simplesmente reunidos, mas estão associados e são interdependentes. Descobrir essa conexão e ordem dos fenômenos em uma área é uma tarefa científica (SAUER, 1998).

Sendo assim, conforme Sauer (1988), a Geografia baseia-se na realidade, na união dos elementos físicos e culturais da Paisagem, ou seja, nas qualidades físicas da área que são importantes para a sociedade e nas formas do seu uso da área, em fatos de base física e fatos da cultura humana.

Com base nessa conceituação, pode-se distinguir duas grandes dimensões no âmbito do conceito: a primeira metade, da área física (Paisagem Natural), que engloba o somatório de todos os recursos naturais que a sociedade tem à sua disposição na área; e a segunda metade, a expressão cultural (Paisagem Cultural), correspondente à forma estritamente geográfica de se pensar a cultura, a saber, a marca da ação do homem sobre a área (SAUER, 1998).

No tocante à dimensão antrópica, a modificação da área pela sociedade e sua apropriação para o seu uso são importantes para a ocorrência da sucessão dessas paisagens como uma sucessão de culturas. Sendo assim, a Paisagem Natural é submetida a uma transformação social, o último e na visão de Sauer (1998), o fator mais importante.

Desta forma, tem-se o método morfológico de síntese, onde a agregação e o ordenamento dos fenômenos como formas estão integradas em estruturas, as quais devem ser objeto de estudo comparativo, isto é, num específico método empírico, apoiado nos seguintes postulados:

I. que existe uma unidade de qualidade orgânica ou quase orgânica, ou seja, uma estrutura (...);

II. que a semelhança de formas em estruturas diferentes é reconhecida em função da equivalência funcional (...);

III. que os elementos estruturais podem ser dispostos em série, especialmente em sequiência de desenvolvimento (SAUER, 1998, p. 31).

Em síntese, Sauer (1998) postula a abordagem da Paisagem em termos de suas relações 
associadas ao tempo, bem como suas relações vinculadas ao espaço, subdividindo o conceito em um processo constante de desenvolvimento ou dissolução e substituição ou sucessão.

\section{Paisagem e o Sistema Funcional Geográfico}

Seguindo uma linha de estudo alemã e permeada pela contribuição de autores interessados em questões ambientais e nas relações sociedade-natureza, essa visão do conceito postula que a Geografia não se limita à observação e à descrição do visível, ainda que parta delas, mas que deve compreender a natureza do conjunto dos elementos constitutivos da superfície terrestre, isto é, os fenômenos espaciais, o entrelaçado de suas relações e a sua sucessão temporal (BOBEK e SCHMITHÜSEN, 1998).

Seguindo essa linha, enquanto objetos de investigação, os espaços da superfície terrestre devem ser concebidos não como entidades tridimensionais, mas sim, quadridimensionais, como complexos de fenômenos espaço-temporais. Dada a sua natureza, participam do mundo inorgânico, do mundo da vida e do mundo do espírito, não somente justapostos ou interconectados, mas essencialmente integrados (BOBEK e SCHMITHÜSEN, 1998).

Esse delineamento geral consiste no âmago de diversos estudos da natureza, feitos de forma integrada e enquadrados na proposta metodológica conhecida como "fisiologia da paisagem" (CONTI, 2001).

No domínio do inorgânico o interesse da Geografia não chegaria até as unidades elementares, se detendo aos sistemas ou complexos que na Paisagem desempenham o papel de elementos básicos, reunidos em um determinado espaço e que encontram-se entrelaçados por múltiplas relações, cujo funcionamento é regido por leis de causalidade (BOBEK e SCHMITHÜSEN, 1998).

Ao contrário dos componentes abióticos, os indivíduos do mundo orgânico podem entrar diretamente para formar parte da Paisagem como verdadeiras unidades elementares da mesma. Os seres vivos não são simples produtos de seu meio; tampouco são propriamente autônomos em relação a ele, mas podem, em maior ou menor grau, resistir e contrapor sua influência e acomodá-la às suas condições de vida. Sendo assim, os objetivos fundamentais da análise geográfica da Paisagem são descobrir a ordem dentro da multiplicidade, decompô-la e explicar com clareza o emaranhado de relações recíprocas que nela se dá (BOBEK e SCHMITHÜSEN, 1998).

No Brasil, a maior contribuição aos estudos sobre as paisagens naturais foi de Ab'Saber, que promoveu uma renovação metodológica e instrumental nas pesquisas geomorfológicas desenvolvidas no território nacional. Recuperando o conceito de fisiologia da paisagem, Ab'Saber compreendeu a paisagem como sendo o resultado de uma relação entre os processos passados e os atuais. Assim, os processos passados foram os responsáveis pela compartimentação regional da superfície, enquanto que os processos atuais respondem pela dinâmica atual das paisagens (VITTE, 2007). 


\section{Paisagem-Marca e Paisagem-Matriz}

Essa abordagem, nitidamente cultural, aponta para um duplo papel da Paisagem Geográfica, onde ela é simultaneamente uma marca, uma grafia, que o homem imprime na superfície terrestre e que reflete a natureza da sociedade que realiza a grafia; e ao mesmo tempo, as marcas constituem matrizes, isto é, as condições para a existência humana (BERQUE, 1998).

Dito de outra forma: é preciso compreender a Paisagem de dois modos: por um lado, vista por um olhar, apreendida por uma consciência e valorizada por uma experiência, julgada (e eventualmente reproduzida) por uma estética e uma moral, gerada por uma política, por exemplo, e; por outro lado, ela é matriz, ou seja, determina em contrapartida, esse olhar, essa consciência, essa estética, essa moral e essa política (BERQUE, 1998).

Sob esse enfoque cultural, a ideia da paisagem merece mais atenção pela avaliação ambiental e estética (HOWLEY et al., 2012; HOWLEY, 2011; KALTENBORN e BJERKE, 2002; NADENICEK, 1997). Neste sentido, o conceito de Paisagem depende muito da cultura das pessoas que a percebem e a constroem, se constituindo, assim, num produto cultural resultado do meio ambiente sob ação da atividade humana, apresentando na sua configuração, marcas culturais e recebem, assim, uma identidade típica (SCHIER, 2003).

Como manifestação concreta, a Paisagem está naturalmente exposta à objetivação analítica do tipo positivista; mas ela existe, em primeiro lugar, na sua relação com o sujeito coletivo: a sociedade que a produziu, que a reproduz e a transforma em função de uma certa lógica. A Paisagem é uma marca, pois expressa uma civilização, e como marca, a Paisagem pode e deve ser descrita e inventariada (BERQUE, 1998).

Do ponto de vista pragmático, essa Paisagem Cultural apresenta elementos para o uso prático e de valor teórico como uma ferramenta de análise de turismo, que pode ser embasada, por sua vez, no conceito de Patrimônio Mundial, onde a Paisagem cultural é uma categoria que efetivamente representa igualmente, em termos de patrimônio humano, paisagens naturais, como grandes parques nacionais do mundo e heranças culturais, como grandes edifícios e estruturas históricas do mundo (BUCKLEY et al., 2008).

Outra forma de aplicação verifica-se na gestão de áreas ambientalmente protegidas, onde, por meio do conceito de Paisagem Cultural, pode-se gerir e proteger determinadas áreas em seus aspectos sociais e culturais, garantindo a sustentabilidade do turismo (COY e WEIXLBAUMER, 2007).

Saule-Sorbé (2010) ressalta ainda que a Paisagem pode ser entendida uma representação comum na prática da arte e ciência, uma vez que fornece uma maneira estruturada de ver as coisas concretas, as ideias abstratas, onde a imagem apresenta uma função documental e educacional, apresentando o viés artístico como forma de análise cultural da paisagem.

Por fim, não se pode esquecer do âmbito da Paisagem Urbana, atrelada ao aspecto cultural, a qual, de maneira geral, deve ser entendida como um fenômeno cultural, é uma convenção, e como tal, 
varia de uma cultura para outra e também de um período para outro (MADERUELO, 2010).

Desta forma, conforme Maderuelo (2010), uma vez que é possível delinear o conceito de "paisagem" como um fenômeno cultural e não apenas como um produto causal da natureza ou como uma construção física, entendo-a como um fenômeno subjetivo, se lança a ideia da cidade como um lugar capaz de causar sensações estéticas e sentimentos emocionais, devendo, portanto, ser interpretada como "paisagem".

\section{Cultura e Simbolismo nas Paisagens Humanas}

Reforçando a adoção da abordagem cultural nos estudos sobre a Paisagem, mas efetivamente calcada numa análise fundada no simbolismo, tem-se a Paisagem intimamente ligada com a cultura, com a ideia de formas visíveis sobre a superfície da Terra e sua composição, como uma maneira de ver, de compor e harmonizar o mundo externo em uma unidade visual (COSGROVE, 1998).

Sob esse entendimento, ter-se-iam dois tipos fundamentais de paisagens geográficas. O primeiro é a "Paisagem da cultura dominante", um dos meios através do qual um determinado grupo exerce o seu poder; e o segundo tipo, denominado de "paisagens alternativas" ou paisagens residuais, emergentes e excluídas. Por sua natureza, as culturas alternativas são menos visíveis na Paisagem do que as dominantes, apesar de que, com uma mudança na escala de observação, pode parecer dominante uma cultura subordinada ou alternativa (COSGROVE, 1998).

Sendo assim, o caráter simbólico na Paisagem Cultural traz a análise para o campo da representação, do discurso e da ideologia, ampliando o foco analítico do estudo e da caracterização das morfologias que a cultura material imprime no espaço (ROZO, 2010).

Para Vitte (2007), por meio do conceito de paisagem, o imaginário social transforma culturalmente a natureza, ao mesmo tempo, que os sistemas técnicos agregam ao território as formasconteúdo da paisagem, constituídas por representações sociais, as quais, inclusive, podem questionar a aplicabilidade e validade do conceito (GRONING, 2004).

Como pode-se perceber, essa linha de análise apresenta-se ainda mais abrangente que as demais, onde a paisagem é cada vez mais entendida como a união das dimensões físicas, mentais, natural e cultural da existência humana, ao passo que o conceito pode ser, inclusive, um indicativo de bem-estar como base das percepções, perspectivas, discursos e papéis de grupos sociais locais (HIGGINS et al., 2012; HERRERA et al.,2011; RODIEK, 1988).

\section{Unidade de Paisagem}

Um dos conceitos de maior importância em estudos de paisagem é, sem dúvida, a unidade de paisagem, reunindo em uma ideia de todo, os "fatores e relações naturais e / ou humanas", o qual pode ser elaborado através da regionalização, compartimentação e delimitação de determinadas áreas que apresentam alguma grau de homogeneidade (GINÉ, 2012). 
Esta homogeneidade, conforme Giné (2012), pode se dar a partir de um ponto de vista fisionômico ou perceptivo, ou de um ponto de vista interno e/ou de funcionamento, podendo considerar os fluxos de energias e as inter-relações também. Atrelado a isso, vale ponderar a tarefa complexa de delimitação das unidades de paisagem, sobretudo pelo fato de que, raramente, a delimitação se faz de forma brusca, nítida.

Em função do caráter de visibilidade tão característico do conceito de paisagem, enquanto objeto geográfico, tem-se a ampla possibilidade de cartografá-la, o que, em consonância com o importante conceito de escala (HIGGINS et al., 2012), permite a hierarquização de unidades de paisagem em classes de paisagem (MAXIMIANO, 2004), como foi realizado, por exemplo, por Katzer (1903), ao subdividir o território cearense em 04 "paisagens": praia, planície regada, sertão e serra", ou mais recentemente, por Rodriguez e Silva (2002).

Não obstante, percebe-se que a cartografia apresenta-se como uma apropriada forma, dentre outras, de representação das unidades de paisagem. Contudo, a questão metodológica fundamental para o discernimento das paisagens é a das escalas temporo-espaciais (MARTINELLI e PEDROTTI, 2001), as quais devem ser claramente definidas para a uma maior aproximação da abordagem evolutiva.

\section{Ecologia da Paisagem}

Esse viés mais recente é fundado em uma concepção de natureza ordenada como um todo, onde a Paisagem se apresenta como uma expressão fisionômica, visível, da organização natural (CANTERO, 2010), que busca oferecer novas percepções sobre os processos que atuam em diferentes estruturas espaciais e escalas. Este entendimento pode ser útil para o planejamento que esteja envolvido principalmente na optimização da utilização do espaço ou à melhoria das condições ambientais (ANTROP, 2001), sejam elas presentes ou pretéritas (CARAVELLO e GIACOMIN, 1993).

O ponto de partida desta abordagem é a atribuição à paisagem expressar visualmente a qualidade da ordem, organização, ou estrutura, da realidade geográfica. Não só revelar as formas em que se manifesta em superfície terrestre, mas também o que é mais importante, as manifestações da ordem interna que a sustenta e condiciona (CANTERO, 2010). Em primeiro lugar, a Ecologia da Paisagem descreve a estrutura do ambiente físico e biológico em uma escala que é prática para os seres humanos; em segundo lugar, descreve processos dinâmicos no tempo e no espaço, e explora as maneiras pelas quais as estruturas moldam os processos (GOLLEY e BELLOT, 1991).

Considerando que o futuro da maioria das paisagens tende a ser cada vez mais alterado e/ou determinado pelas atividades humanas, as quais modificam os padrões existentes de paisagem, entendê-los, segundo Hobbs (1997), é essencial para o planejamento do uso da terra e sua gestão racional, cujo entendimento seria o foco da Ecologia da Paisagem. 
Naveh (1995) aponta que a compreensão das interações entre paisagens e as forças culturais é essencial para a sua gestão sustentável, em um contexto de aproximação entre a Ecologia da Paisagem e o conceito de Paisagem Cultural.

Esta forma de análise apresenta ainda como uma importante característica seu caráter interdisciplinar, o qual engloba uma análise complexa que, na maioria das vezes, requer uma priorização dos diferentes fatores: ecológicos, econômico e social. Todavia, vale ressaltar que os limites da interdisciplinaridade estão relacionados com a necessidade de reduzir determinadas áreas temáticas ou técnicas disciplinares de investigação para que certos dados possam ser usados em escalas compatíveis e interessantes em um contexto interdisciplinar (BERTRAND e VANPEENEBRUHIER, 2007).

\section{Elementos-síntese do conceito}

Traçando paralelos e sintetizando as diversas abordagens do conceito de Paisagem, percebe-se aspectos comuns, ou elementos de síntese na abordagem desse conceito-chave geográfico, seja como objeto de interesse de pesquisa, seja como método de estudo. Baseado em Maximiano (2004), seriam eles:

I. $\mathrm{O}$ aspecto fundamentalmente visual;

II. A análise dos aspectos morfológicos;

III. A complexidade de inter-relações entre os elementos físicos e destes com os elementos culturais;

IV. A abordagem do aspecto cultural;

V. A Sucessão temporal das diferentes paisagens;

VI. A possibilidade de cartografar a paisagem, já que a mesma ocupa um lugar, e a diversidade da escala da paisagem - do local ao planetário;

VII. A possibilidade de classificar paisagens em unidades diferenciadas ou homogêneas ou com ênfase em um elemento de sua composição - vegetação, clima ou cultura;

VIII. O caráter dinâmico das paisagens; e

IX. A possibilidade de análise por meio dos elementos, estrutura e/ou funcionamento da paisagem.

X. A adoção do parâmetro espacial-evolutivo para a análise da Paisagem.

\section{CONCLUSÕES}

Assim como os demais conceitos-chave do conhecimento geográfico, o conceito de Paisagem apresenta no curso de sua história, apresentado aqui desde sua gênese, passando pela sua retomada nos anos 1970 e culminando com a apresentação dos seus aspectos mais contemporâneos, uma significativa diversidade de abordagens, agrupadas neste trabalho em suas linhas principais de análise, 
todas elas, diga-se de passagem, com amplas possibilidades de aplicação.

Essa diversidade de linhas de análise engloba suas perspectivas básicas, as quais tratam dos aspectos morfológicos e fisiológicos, os quais nunca foram escamoteados, tampouco superados no decurso da evolução do conceito, ao contrário, foram aglutinados junto de aspectos culturais e simbólicos, em formas mais abrangentes de análise da Paisagem, onde os aspectos sociais, humanos, são levados para o centro das discussões.

Exatamente seguindo essa linha imbricada de sucessão das formas de análise, atualmente o conceito apresenta abordagens que adotam os aspectos básicos do conceito, a abordagem culturalsimbólica, em conjunto com estudos de regionalização, compartimentação e delimitação de áreas homogêneas, os quais configurando-se em importantes exercícios de síntese, as Unidades de Paisagem; e a Ecologia da Paisagem, que traz para o âmbito analítico do conceito as preocupações conservacionistas e com a necessária melhoria das condições ambientais.

Por fim, apesar da diversidade de formas de análise, percebe-se um conjunto de aspectos comuns entre essas abordagens, ou seja, o aspecto visual, morfológico e funcional do conceito, a abordagem cultural e de sucessão temporal, de apoio no conceito de escala e das ferramentas cartográficas, por conseguinte, de classificação e, por fim, da adoção do parâmetro espacial-evolutivo para a análise da Paisagem.

Esses aspectos comuns entre as diferentes abordagens analisadas garantem unidade $\mathrm{e}$ diversidade analítica ao conceito de Paisagem, o qual propicia uma ampla diversidade de possibilidades de aplicação no contexto da Ciência Geográfica.

\section{AGRADECIMENTOS}

O autor agradece ao Prof. Dr. José Borzacchiello da Silva, do Programa de Pós-Graduação em Geografia da UFC, pelas sugestões e pela gentileza na revisão do manuscrito original, apresentado na disciplina do Mestrado em Geografia, o qual embasa a discussão tratada neste trabalho.

A Fundação Cearense de Apoio ao Desenvolvimento Científico e Tecnológico - FUNCAP financiou parte do trabalho de pesquisa que resultou nas conclusões contidas neste trabalho, através da concessão da bolsa de estudo para o autor Marcelo Moura-Fé, vinculada ao Programa de PósGraduação em Geografia da UFC. 


\section{REFERÊNCIAS}

ANTROP, M. The language of landscape ecologists and planners. A comparative content analysis of concepts used in landscape ecology. Landscape and Urban Planning, n. 55, p. 163-173, 2001.

BERQUE, A. Paisagem-Marca, Paisagem-Matriz: elementos da problemática para uma Geografia Cultura. In: CORRÊA, R. L. e ROSENDAHL, Z. (org.) Paisagem, tempo e cultura. Rio de Janeiro: EdUERJ, 1998.

BERTRAND, N. e VANPEENE-BRUHIER, S. Periurban landscapes in mountain areas. Revue de géographie alpine/Journal of Alpine Research, n. 95, vol. 4, 2007.

BOBEK, H. e SCHMITHÜSEN, J. A Paisagem e o sistema lógico da Geografia. In: CORRÊA, R. L. e ROSENDAHL, Z. (org.) Paisagem, tempo e cultura. Rio de Janeiro: EdUERJ, 1998.

BUCKLEY, R.; OLLENBURG, C. e ZHONG, L. Cultural landscape in mongolian tourism. Annals of Tourism Research, vol. 35, n. 1, p. 47-61, 2008.

CANTERO, N. O. El lugar del paisaje en la geografía moderna. Estudios Geográficos, vol. LXXI, n. 269, p. 367-393, 2010.

CARAVELLO, G. U. e GIACOMIN, F. Landscape ecology aspects in a territory centuriated in Roman Times. Landscape and Urban Planning, n. 24, p. 77-85, 1993.

CONTI, J. B. Resgatando a "Fisiologia da Paisagem". Revista do Departamento de Geografia, n. 14, p. 59-68, 2001.

CORRÊA, R. L. Espaço, um conceito-chave da Geografia. In: CASTRO, I. E. et al (org.).

Geografia: conceitos e temas. Rio de Janeiro: Bertrand Brasil, 1995.

CORRÊA, R. L. e ROSENDAHL, Z. (org.). Paisagem, tempo e cultura. Rio de Janeiro: EdUERJ, 1998.

COSGROVE, D. A Geografia está em toda parte: cultura e simbolismo nas Paisagens Humanas. In: CORRÊA, R. L. e ROSENDAHL, Z. (org.) Paisagem, tempo e cultura. Rio de Janeiro: EdUERJ, 1998.

COY, M. e WEIXLBAUMER, N. Perception de la gestion du paysage. Revue de géographie alpine/Journal of Alpine Research, n. 95, vol. 4, 2007.

GIL, A. C. Como elaborar projetos de pesquisa. 3 ed. São Paulo: Atlas, 157p. 1996.

GINÉ, D. S. Consideraciones en torno al concepto de unidad de paisaje y sistematización de propuestas. Estudios Geograficos, vol. LXXIII, n. 272, p. 215-237, 2012.

GOLLEY, F. B. e BELLOT, J. Interactions of landscape ecology, planning and design. Landscape and Urban Planning, n. 21, p. 3-21, 1991.

GRONING, G. A questionabilidade do conceito de paisagem. Revista RA'E GA, n. 8, p. 9-18, 2004.

HERRERA, M. C. P.; BASSOLS, N. B. e McCALL, M. Gestión y cultura del agua desde la perspectiva del paisaje en la cuenca del río Huámito, Michoacán, México. Perspectiva 
Geográfica, vol. 16, p. 9-30, 2011.

HIGGINS, S.; MAHON, M. e MCDONAGH, J. Interdisciplinary interpretations and applications of the concept of scale in landscape research. Journal of Environmental Management, n. 113, p. 137-145, 2012.

HOBBS, R. Future landscapes and the future of landscape ecology. Landscape and Urban Planning, n. 37, p. 1-9, 1997.

HOWLEY, P. Landscape aesthetics: assessing the general public's preferences towards rural landscapes. Ecological Economics, n. 72, p. 161-169, 2011.

HOWLEY, P.; DONOGHUEA, C. O. e HYNES, S. Exploring public preferences for traditional farming landscapes. Landscape and Urban Planning, n. 104, p. 66-74, 2012.

KALTENBORN, B. P. e BJERKE, T. Associations between environmental value orientations and landscape preferences. Landscape and Urban Planning, n. 59, p. 1-11, 2002.

KATZER, F. Paizagens do Ceará. Trad. Capistrano de Abreu. Revista do Instituto do Ceará, 1903.

MADERUELO, J. EI Paisaje Urbano. Estudios Geográficos, vol. LXXI, n. 269, p. 575-600, 2010.

MARTINELLI, M. e PEDROTTI, F. A Cartografia das Unidades de Paisagem: questões metodológicas. Revista do Departamento de Geografia, n. 14, p. 39-46, 2001.

MAXIMIANO, L. A. Considerações sobre o Conceito de Paisagem. Revista RA`E GA, n. 8, p. 8391, 2004.

MENDONÇA, F. Geografia e Meio ambiente. São Paulo: Contexto, 1997.

MONTSERRAT, J. Paisaje: uma síntesis geográfica? Revista de Geografia, vol. XXIV. Barcelona, 1990.

MORAES, A. C. R. Geografia. Pequena história crítica. 14 ed. São Paulo: Hucitec, 1998.

NADENICEK, D. J. The poetry of landscape ecology: an historical perspective. Ladscape and Urban NAVEH, Z. Interactions of landscapes and cultures. Landscape and Urban Planning, n. 32, p. 4354,1995

RODIEK, J. The Evolving Landscape. Landscape and Urban Planning, n. 16, p. 35-44, 1988.

RODRIGUEZ, J. M. M. e SILVA, E. V. S. Classificação das Paisagens a partir de uma visão geossistêmica. Revista Mercator, n. 01, 2002.

ROZO, J. D. D. Entre la materialidad y la representación: reflexiones sobre el concepto de paisaje en geografía histórica. Cuadernos de Geografía - Revista Colombiana de Geografía, n. 19, p. 77-86. Bogotá - Colômbia, 2010.

SAUER, C. O. A Morfologia da Paisagem. In: CORRÊA, R. L. e ROSENDAHL, Z. (org.) Paisagem, tempo e cultura. Rio de Janeiro: Ed UERJ, 1998.

SAULE-SORBÉ, H. Art et géographie dans les représentations modernes du paysage, le cas des Pyrénées. Estudios Geográficos, vol. LXXI, n. 269, p. 475-504, 2010.

SCHIER, R. A. Trajetórias do conceito de Paisagem na Geografia. Revista RA`E GA, n. 7, p. 79$85,2003$. 
VITTE, A. C. O desenvolvimento do conceito de Paisagem e sua inserção na Geografia Física. Revista Mercator, n. 11, p. 71-78, 2007.

XIMENES, S. Minidicionário da Língua Portuguesa. Rio de Janeiro: Ediouro, 2003. 